\title{
Understanding mistreatment during institutional delivery in Northeast Nigeria: a mixed-method study
}

\author{
Nasir Umar ${ }^{1 *}$ (D), Deepthi Wickremasinghe ${ }^{1}$, Zelee Hill², Umar Adamu Usman ${ }^{3}$ and Tanya Marchant ${ }^{1}$
}

\begin{abstract}
Background: Improving quality of care including the clinical aspects and the experience of care has been advocated for improved coverage and better childbirth outcomes.

Objective: This study aimed to explore the quality of care relating to the prevalence and manifestations of mistreatment during institutional birth in Gombe State, northeast Nigeria, an area of low institutional delivery coverage.

Methods: The frequency of dimensions of mistreatment experienced by women delivering in 10 health facilities of Gombe State were quantitatively captured during exit interviews with 342 women in July-August 2017. Manifestations of mistreatment were qualitatively explored through in-depth interviews and focus groups with 63 women living in communities with high and low coverage of institutional deliveries.

Results: The quantitative data showed that at least one dimension of mistreatment was reported by $66 \%$ (95\% confidence interval (Cl) 45-82\%) of women exiting a health facility after delivery. Mistreatment related to health system conditions and constraints were reported in 50\% (95\% Cl 31-70\%) of deliveries. In the qualitative data women expressed frustration at being urged to deliver at the health facility only to be physically or verbally mistreated, blamed for poor birth outcomes, discriminated against because of their background, left to deliver without assistance or with inadequate support, travelling long distances to the facility only to find staff unavailable, or being charged unjustified amount of money for delivery.

Conclusions: Mistreatment during institutional delivery in Gombe State is highly prevalent and predominantly relates to mistreatment arising from both health system constraints as well as health worker behaviours, limiting efforts to increase coverage of institutional delivery. To address mistreatment during institutional births, strategies that emphasise a broader health systems approach, tackle multiple causes, integrate a detailed understanding of the local context and have buy-in from grassroots-level stakeholders are recommended.
\end{abstract}

Keywords: Quality of care, Respectful maternity care, Mistreatment, Maternal and newborn health, Mixed-methods

\section{Plain English summary}

There is growing evidence from Nigeria and around the world that women who deliver their babies in health facilities can experience mistreatment. In our study, we describe how frequently this happens in Gombe state, north-eastern Nigeria, and what type of mistreatments women experience. Using a questionnaire, we interviewed consenting women as they left the facility after

\footnotetext{
* Correspondence: nasir.umar@lshtm.ac.uk

'Department of Disease Control, London School of Hygiene \& Tropical Medicine, London WC1E 7HT, UK

Full list of author information is available at the end of the article
}

birth and asked them about events that occurred during their labour and delivery, and their perception of the care that health workers provided. In addition, through in-depth interviews and focus group discussions, we talked to women with young infants about mistreatment at birth and asked them to try to explain their experiences to us. At least one type of mistreatment was reported by $66 \%$ of the women. About $50 \%$ of mothers experienced mistreatment due to poor health system conditions and constraints, for example staff shortages or staff not having the commodities they needed to provide care. And $46 \%$ experienced mistreatment related to 
having poor rapport with the provider, for example being denied a birth companion, examined without permission or not allowed to give birth in their preferred position. Both health system constraints and poor health worker behaviours limit efforts to increase coverage of institutional delivery. Immediate and sustained attention to the quality of care as it pertains to the experience of users is needed.

\section{Background}

Institutional delivery is advocated to improve maternal and newborn health outcomes [1, 2]. Globally, the majority of births now occur in a health facility [3], although, high coverage is not uniform [3]. Nigeria continues to have suboptimal institutional delivery coverage, being 39\% in 2018 [4]. Among the reasons consistently cited by women for not delivering in a health facility were concerns relating to a perception of poor quality of services $[5,6]$. A combination of the effectiveness of care given and the negative experience from services received shapes users' perception of care, which in turn influences health-seeking behaviour [7].

Considering every pregnant woman is at risk of obstetric complication [8,9], access to timely and appropriate obstetric care remains imperative $[10,11]$. Health systems should therefore, strive to improve the quality of care provided to women during institutional delivery, both in terms of process quality and experience of care, to guarantee the fundamental rights of women, encourage utilisation and ensure improved outcomes [12-14].

One limitation to addressing the negative experience of care has been the difficulty in defining and measuring the problem $[15,16]$. But, recent developments from the characterisation of disrespect and abuse by Bowser and Hill [17], and a revised typology by Bohren et al. [18], have furthered the review of quality of care as it relates to women's experience or perception of care received during institutional delivery $[12,15,18,19]$. These developments allow for comparison with the expected standard of care, and where the care provided falls short of agreed standards, highlights opportunities for improvement [20-23]. However, evidence from Nigeria continues to be scarce [24].

This study was conducted in Gombe state one of six northeastern states of Nigeria. The quality of maternal and newborn health (MNH) services are suboptimal in Nigeria, but also varies between states, in part due to the resources committed to health by individual states [25]. In Gombe State, more than $60 \%$ of women still deliver at home [26], in part because of cultural or religious beliefs, cost or geographical access [4, 27-30]. Infrastructural and personnel deficiencies, and attitude of health workers, have also been suggested as possible deterrents
$[25,27]$, as might be the fear of mistreatment, although there is no evidence to support this assumption.

In this study, we aimed to explore the quality of care relating to the prevalence and manifestations of mistreatment during institutional birth in Gombe State, northeast Nigeria, where maternal mortality and morbidity is persistently high and access to health care suboptimal $[26,31]$. We describe the frequency of different dimensions of mistreatment reported by women and use qualitative methods to explore the manifestations of mistreatment in this setting.

\section{Methods}

\section{Study setting}

Gombe State has an estimated population of 2.6 million based on the last census in 2006. Gombe State has 11 Local Government Areas, is multi-ethnic and $80 \%$ rural $[32,33]$. The state has a high maternal mortality ratio, estimated at 1549 maternal deaths per 100,000 live births, neonatal mortality is estimated at 35 neonatal deaths per 1000 live births and just 29\% of women had delivered their most recent newborn in a health facility [26, 32-34]. Public health services account for $98 \%$ of institutional deliveries in the state [26, 32-34]. In Gombe State, approximately 486 public health facilities provide labour and delivery services 460 of which are primary health facilities and 28 are referral facilities offering both labour and delivery services and specialised care [35]. Lower cadre health care workers, for example, community health extension workers (CHEW), junior community health extension workers (JCHEW) and community health officers $(\mathrm{CHO})$ comprise the majority of the health care workforce [36].

In primary health care facilities, nurses or midwives are responsible for the organisation and provision of MNH services with the assistance of CHEWs, JCHEWs or any lower cadre health worker available. In the absence of nurses of midwives these lower cadre health workers must take full responsibility. In most of the $\mathrm{PHCs}$, health care providers are not available $24 \mathrm{~h}$ a day, limiting access to facility-based care in case of an emergency or a delivery outside daylight hours. This problem is less acute in referral health facilities where nurses or midwives contribute to the organisation and delivering of $\mathrm{MNH}$ services under the supervision of a medical doctor.

\section{Study design}

Quantitative and qualitative data were collected in 2017, as part of a programme of work to understand the quality of maternal and newborn care in Gombe State. The quantitative study involved conducting structured exit interviews with recently delivered women upon discharge after institutional delivery, in 10 primary health 
care facilities. The qualitative study included in-depth interviews (IDIs) and focus groups with 63 women who had recently delivered in a health facility in two local government areas (LGAs) (districts): Kaltungo, characterised by higher levels of facility births, and Kwami, where there are low levels of facility deliveries, and are reported below in line with the Consolidated Criteria for Reporting Qualitative Research (COREQ) [37].

This research was conducted with approval from the ethics review boards of the Federal Ministry of Health Abuja, Nigeria, the State Ministry of Health Gombe State, Nigeria and the London School of Hygiene \& Tropical Medicine (reference 12,181). To obtain participant's informed consent, all potential participants were provided with study information sheet and a consent form. The information sheet provided information to the participants about their right to participate or refuse to participate in the study, the right to change their mind about participating during the course of the study, and the right to withdraw from the study at any time. The information sheet was read and explained to those participants that cannot read. The free and written informed consent of all interviewees was obtained. Participants unable to sign the consent form were allowed to thumb print, to affirm their consent.

\section{Quantitative data collection}

A random sample of 107 health facilities was drawn from approximately 500 public primary health facilities. Volume of births occurring in the previous six months in the 107 sampled primary health facilities was determined by reviewing their maternity registers, and the 10 primary health facilities with the highest volume of births in the state were selected for the study. The 10 selected facilities had an average of 15.7 births (SD 12.0) per month, which is higher than the state-level average of 4.3 births (SD 6.3) per month in primary health facilities [35]. The facilities were primary health facilities, providing all services (e.g. primary care, pregnancy care, labour and delivery services). Emergency care and complicated cases from these health facilities are referred to referral health facilities.

All women giving birth in these facilities in July-August 2017, and who had a live newborn, were invited to complete an exit interview about events that occurred during their labour and delivery, and their perception of the care that health workers provided, including respectful care. To ensure confidentiality, the exit interviews were conducted in a separate room or area reserved for the interviews within the health facilities. In each of these 10 facilities, two trained data collectors and a supervisor were posted in shifts covering day and night deliveries, seven days a week for approximately four weeks. This was determined to be the amount of time needed in these high- volume facilities to recruit a sample of 320 births. The sample size was calculated based on the assumed prevalence of respectful maternity practices of $10-20 \%$, a power of $80 \%$, a $95 \%$ confidence interval.

\section{Study instrument}

The study instrument was a structured questionnaire covering the demographic information of study participants, the content of care provided to the mother and the newborn, and respectful care during institutional birth. The study tool was operationalised based on revised typology by Bohren et al. [18] The tool had 31 items, structured around the seven domains of mistreatment proposed by Bohren and others: physical abuse (2items), sexual abuse (1-item), verbal abuse (2-items), stigma and discrimination (1-item), failure to meet professional standards of care (6-items), poor rapport between women and health providers (11-items), and health system conditions and constraints (8-items) [18]. Additional file 1: Table S1 present questions used to assess mistreatment during institutional delivery in Gombe State. Women were asked to provide Yes or No response to the questions listed in Additional file 1: Table S1. This method is widely used in attitude measurement, for example, in Abuya et al. [23] and easily understood by respondents [38]. The study instrument was first reviewed and validated for content in collaboration with a group of health workers (doctors, nurses and midwives) working in Gombe. The tool was pilot tested within the same study health facilities with postpartum women. The feedback from the health workers and the pilot informed further refinement and finalisation of the study instrument. Data were collected using personal digital assistants, programmed in Census and Survey Processing System (CSPro), and took about an hour to complete.

\section{Quantitative data analysis}

Descriptive statistics about the study sample of postpartum mothers and their reported experience of respectful maternity care were tabulated. An aggregate outcome variable on the report of any abuse was computed from each of the seven domains. We used the svyset command in Stata 15 to account for clustering at the facility level.

\section{Qualitative data collection}

In December 2017, IDIs and focus groups were conducted with consenting women who had recently delivered in a health facility in Kaltungo and Kwami LGAs. Similar to rest of Gombe State, Kaltungo and Kwami LGAs are multi-ethnic and mostly rural. Public health services account for almost all institutional deliveries in these LGAs, provided through 38 public and six private 
health facilities in Kaltungo LGA, and 42 public health facilities in Kwami LGA, where there are no private health facilities. Recruitment was purposeful and involved the lead researcher with the assistance of health facility staff identifying women who had delivered in a health facility, from the records of two health facilities in Kaltungo LGA and two health facilities in Kwami LGA, and whose infants were under 6-months of age. The homes of 64 eligible women were then identified with the assistance of community leaders specifically ward focal persons.

The IDIs were conducted in the two most commonly spoken local languages in Gombe, Hausa and Fulfulde, and in English, using a pretested semi-structured interview guide. Out of the 64 women identified and recruited, 31 women - 15 in Kaltungo and 16 in Kwami - were interviewed in-depth before sufficient saturation level was achieved, determined in reflective meetings inbetween interviews [39]. One of the women recruited for the IDIs in Kaltungo could not participate because she travelled out of town before the interview. The interviews were conducted in the women's homes or in a private place of their choosing, by a trained female interviewer. Interview sessions lasted between 60 and $90 \mathrm{~min}$, and were audio recorded, the research lead ensured the quality of the data collected from the IDIs through reflective meetings with the interviewer between the interviews. The interviews focused on problems faced by pregnant women, their motivations for giving birth in a health facility and for selecting a particular health facility, their attitudes towards health facility deliveries, their perceptions of quality of care and experience of mistreatment during institutional delivery.

The IDIs were followed by focus group discussions (FGDs) to gain further insights into the women's shared understandings of respectful care during institutional delivery and to gain group consensus around themes identified in the IDIs as reasons for giving birth in a health facility and perceptions of quality of care, including respectful care received. Four FGDs were conducted, two in Kwami LGA and two in Kaltungo LGA, with the remaining 32 women from the 64 originally identified. Eight women participated in each FGD with no stratification. For optimal results, 6-12 participants per focus group were recommended $[40,41]$. The FGDs were also conducted by a trained female interviewer, assisted by the research lead. To encourage participants to speak freely the FGDs were conducted in neutral settings: empty primary school classrooms and community centre conference rooms. The FGD sessions lasted between 90 and $120 \mathrm{~min}$ [42]. The same trained female interviewer carried out both the IDIs and FGDs. IDI and FGD guides were used to ensure that all relevant issues were covered. Data collection took the form of field notes, supported by recordings. At the end of each data collection session, the sound recordings, field notes and consent forms, were stored securely.

\section{Qualitative data analysis}

The recorded qualitative interviews were transcribed verbatim and translated from Hausa or Fulfulde into English. To ensure that the original meanings conveyed by the participants were fully captured the data collectors also carried out the translations. A thematic content analysis a form of qualitative analysis that allows the use of quantitative results as the basis for a priori themes was used to analyse the data, with a manifest approach [40], in which the data analysis focused on what women said of their experience during labour and delivery. The data analysis was carried out in three stages. First, familiarisation involving reading and re-reading the transcripts to aid understanding of the data. Second, organising and coding the data. The coding was determined a priori to align the qualitative findings to the quantitative results, to aid understanding how the quantitative findings were manifest. These were physical abuse, verbal abuse, sexual abuse, stigma and discrimination, failure to meet professional standards of care, poor rapport between women and providers and health system conditions and constraints. The coding was done using NVivo software version 12. Third, data from each code point were reviewed and summarised to reduce the number of words without losing the content or context of the text and to ensure themes were internally consistent. The a priori themes helped in identifying broad initial themes, further themes that emerged from the analysis were considered sub-divisions of those broad initial themes, but may also be standalone. The qualitative study findings were drawn from individual themes and sub-themes, and from exploring the relationship between themes. Some representative anonymised quotes of women's own words were used to describe the manifestations of their experiences. The credibility of the data was determined by triangulating data between data collection methods.

\section{Results}

\section{Characteristics of women}

The majority of exit interview participants were multigravidae between the ages of 20 and 29 years, from the Fulani or Hausa ethnic groups, nearly all were Muslims, all were married, and half had received no formal education. All women had been attended by female health staff, just $20 \%$ of whom were doctors, nurses or midwives. Around $60 \%$ of births occurred during the daytime and on a weekday (Table 1).

Thirty-one women participated in the IDIs; mostly multigravidae between the ages of 20 and 29 years, 
Table 1 Socio-demographic characteristics of exit interview participants and delivery context

\begin{tabular}{|c|c|}
\hline & $N=342$ \\
\hline \multicolumn{2}{|l|}{ Characteristics \& delivery context } \\
\hline \multicolumn{2}{|l|}{ Age } \\
\hline$<20$ years & $17 \%$ \\
\hline 20-29 years & $57 \%$ \\
\hline 30-39 years & $23 \%$ \\
\hline 40-49 years & $3 \%$ \\
\hline \multicolumn{2}{|l|}{ Ethnicity } \\
\hline Fulani & $60 \%$ \\
\hline Hausa & $20 \%$ \\
\hline Kanuri & $6 \%$ \\
\hline Others & $14 \%$ \\
\hline \multicolumn{2}{|l|}{ Religion } \\
\hline Christian & $2 \%$ \\
\hline Muslim & $98 \%$ \\
\hline \multicolumn{2}{|l|}{ Marital status } \\
\hline Married & $100 \%$ \\
\hline Single/Widowed & $0 \%$ \\
\hline \multicolumn{2}{|l|}{ Education level } \\
\hline None & $49 \%$ \\
\hline Primary & $20 \%$ \\
\hline Secondary \& Post-secondary & $31 \%$ \\
\hline \multicolumn{2}{|l|}{ Parity } \\
\hline Primigravida & $2 \%$ \\
\hline Multigravida & $98 \%$ \\
\hline \multicolumn{2}{|l|}{ Supply side characteristics during delivery } \\
\hline \multicolumn{2}{|l|}{ Sex of birth attendants } \\
\hline Female & $100 \%$ \\
\hline Male & $0 \%$ \\
\hline \multicolumn{2}{|l|}{ Category of birth attendant } \\
\hline $\begin{array}{l}\text { Skilled attendants } \\
\text { (doctors, nurses, midwives) } \\
\text { formally employed }\end{array}$ & $20 \%$ \\
\hline Non-skilled attendants & $80 \%$ \\
\hline \multicolumn{2}{|l|}{ Period of birth } \\
\hline Day time (7.00 am to $7.59 \mathrm{pm})$ & $60 \%$ \\
\hline Night time ( $8.00 \mathrm{pm}$ to $6.59 \mathrm{am})$ & $40 \%$ \\
\hline \multicolumn{2}{|l|}{ Day of birth } \\
\hline Weekdays & $69 \%$ \\
\hline Weekend & $31 \%$ \\
\hline
\end{tabular}

mostly Muslims, mostly married and nearly half of whom had received no formal education. A total of 32 women participated in FGDs; again the majority being multigravidae and aged 20-29years, from the Kanuri and Hausa ethnic groups, the majority were Muslims and married, and more than half had received no formal education (Table 2). All had recently delivered in a health facility, the median age of their infants being 6months at the time of interview.

\section{Reported prevalence and manifestation of respectful maternity care practices during institutional birth} Quantitative data on prevalence of respectful maternity care practices are presented below according to the following dimensions: (a) health system conditions and constraints, (b) poor rapport between women and providers, (c) failure of professional standards of care, (d) physical abuse, (e) verbal abuse, (f) sexual abuse and (g) stigma and discrimination. Qualitative data are presented alongside these dimensions to highlights the manifestation of respectful maternity care practices during institutional delivery. No clear pattern emerged to indicate differences in the manifestations of mistreatment between Kwami LGA and Kaltungo LGA.

Table 2 Socio-demographic characteristics of the in-depth interviews and focus groups discussion participants

\begin{tabular}{|c|c|c|c|}
\hline \multirow[t]{2}{*}{ Characteristics } & $\begin{array}{l}\text { In-depth } \\
\text { Interviews }\end{array}$ & $\begin{array}{l}\text { Focus } \\
\text { Groups }\end{array}$ & $\begin{array}{l}\text { All } \\
\text { Participants }\end{array}$ \\
\hline & $N=31$ & $N=32$ & $N=63$ \\
\hline \multicolumn{4}{|l|}{ Age } \\
\hline$<20$ years & $29 \%$ & $9 \%$ & $19 \%$ \\
\hline 20-29 years & $48 \%$ & $50 \%$ & $49 \%$ \\
\hline 30-39 years & $19 \%$ & $41 \%$ & $30 \%$ \\
\hline 40-49 years & $3 \%$ & $0 \%$ & $2 \%$ \\
\hline \multicolumn{4}{|l|}{ Ethnicity } \\
\hline Fulani & $19 \%$ & $9 \%$ & $14 \%$ \\
\hline Hausa & $13 \%$ & $19 \%$ & $16 \%$ \\
\hline Kanuri & $10 \%$ & $13 \%$ & $11 \%$ \\
\hline Others & $58 \%$ & $59 \%$ & $59 \%$ \\
\hline \multicolumn{4}{|l|}{ Religion } \\
\hline Christian & $35 \%$ & $28 \%$ & $32 \%$ \\
\hline Muslim & $65 \%$ & $72 \%$ & $68 \%$ \\
\hline \multicolumn{4}{|l|}{ Marital status } \\
\hline Married & $84 \%$ & $94 \%$ & $89 \%$ \\
\hline Single/Widowed & $16 \%$ & $6 \%$ & $11 \%$ \\
\hline \multicolumn{4}{|l|}{ Education level } \\
\hline None & $45 \%$ & $63 \%$ & $54 \%$ \\
\hline Primary & $10 \%$ & $3 \%$ & $6 \%$ \\
\hline $\begin{array}{l}\text { Secondary \& } \\
\text { Post-secondary }\end{array}$ & $45 \%$ & $34 \%$ & $40 \%$ \\
\hline \multicolumn{4}{|l|}{ Parity } \\
\hline Primigravida & $32 \%$ & $16 \%$ & $24 \%$ \\
\hline Multigravida & $68 \%$ & $84 \%$ & $76 \%$ \\
\hline
\end{tabular}




\section{Health system conditions and constraints}

During exit interviews, cases of mistreatment relating to health system conditions and constraints were reported in up to half of all deliveries 50\% (95\% CI 31-70). Feeling unclear about the fee structure and health workers making unreasonable requests were reported in 19\% (95\% CI 7$44)$ and $19 \%$ (95\% CI 7-44) of deliveries respectively. In as many as one in four deliveries, respondents reported staffing shortages $24 \%$ (95\% CI 11-44) and the poor physical condition of health facilities $27 \%$ (95\% CI 12-49).

The qualitative data supported the high prevalence of mistreatment related to health system conditions and constraints reported in exit interviews. Participants in in-depth-interviews highlighted the different manifestations of health system constraints, which were further confirmed in the FGDs, including women going to the health facility and not getting care because the staff were not available, or being asked to leave the facility to buy delivery materials (e.g. hand gloves, injections, soap or blade) before they were attended to, or being denied attention because they did not have the money to pay, for example, being denied an intravenous infusion when needed, for lack of money. Women expressed discontent at being asked to fetch water or to clean the delivery room themselves before leaving, being asked to deliver on an uncleaned bed with a clear indication of someone else's blood, delivering on the floor due to lack of beds, feeling uncomfortable due to lack of a fan. Women were unhappy with the unclear fee structure at the health facility, a prevalent feeling among them was that charges for delivery were inconsistent and unjustified. Similarly, women felt the number of items demanded by birth attendants was unnecessary (e.g. two bars of soap, kerosene, or bleach). The presence of too many mosquitos in the delivery room, a dirty environment, or being left exposed with no privacy during birth were also mentioned. Less common manifestations in this dimension included experience of extortion relating to not being attended to without paying what the health workers asked. Consensus among FGD participants was that these constraints inclined some women to opt for home delivery or go to a private clinic if they had the money.

"The doctor prescribed some medicine for me, he calculated the money more than five times, he will calculate and calculate again with his calculator from 700 to 1500 and another 250 Naira, from there I know there was a problem..." (IDI participant, 32 years, \#201)

"We were a lot that day, and this one will deliver that one will deliver, there was no privacy, we were looking at each other just like how baby worms are delivered." (IDI participant, 30 years, \#205) "...after you have delivered they should cover you, but ... I swear that is how they leave you naked ... when a woman delivers she needs some privacy, being naked is not good, the angels of mercy will not come over you when you are naked. It is true." (IDI participant, 32 years, \#107)

\section{Poor rapport between women and providers}

From the quantitative data, instances of mistreatment relating to the poor rapport between women and health workers were the second most prevalent dimension with $46 \%$ of women reporting such experiences (95\% CI 24.4-68.6). Denial or lack of a birth companion during labour and delivery was the most prevalent example of poor rapport between women and providers 28\% (95\% CI 14-49), followed by lack of supportive care from health workers $18 \%$ (95\% CI 6-43). Poor communication with the birth attendant during labour and delivery was reported by $15 \%$ (95\% CI 5-37) of the women.

Women in the IDIs, corroborated those in FGDs, who said they had experienced a poor rapport with a birth attendant and described ineffective communication, such as questions or concerns being ignored, not being informed of what was going to happen to them or their babies, not being informed of test results, health workers discussing the condition of a woman in labour in English knowing she was concerned but could not understand what was being said, or not being received with open arms on arrival. Women further described lack of supportive care as including birth attendants not helping the delivery process, not being sympathetic, caring or kind, being unfriendly for no reason, or not being supportive, for example chasing women away from the facility who did not have delivery items such as gloves. Women lamented their loss of autonomy during labour and delivery, including not being allowed to eat, drink or scream, not being allowed to go to the toilet, asked to urinate or defecate on the delivery bed with no explanation; forced to deliver in a position they were not used to, i.e. lying down instead of squatting. They described feelings of constraint or loneliness because they were not allowed to move around during labour, or their birth companion was not allowed to stay with them - even though the health workers stayed outside and there was no one else in the delivery room. Yet having language and interpretation issues or being denied food, fluids or mobility during labour and delivery were not as frequently reported in exit interviews, at 3\% (95\& CI 1-5) and $4 \%(95 \%$ CI $1-18)$ respectively.

Women questioned the value of institutional delivery in the face of such treatment, and in anticipation of such things happening to them again. Mechanisms to minimise their discomfort included having a strong preference 
for a short stay in a health facility - from labour to delivery to discharge - or praying that a particular staff member would not to be on shift.

"I will get up and squat, and they will say no, I should lie down, I will get up again and sit down and she [birth attendant] will say no, lie down. I did not know how they give birth in a facility [my first time] ...I have never heard of $i t$, I swear I have never heard of giving birth lying down." (IDI participant, 30 years, \#206)

"...exactly, you can hear women saying I pray I don't meet madam so and so today in the facility because of her attitude." (FGD participant, 35 years, \#102_4)

"...they [health workers] asked, was it a delivery and I said yes, she [health worker] said was it my first and I said yes again, she took me in, checked and said the baby was not due yet, she was rude, ... and went out to continue talking with her friends. Whenever I tell her I need something like going to pee she wouldn't even talk to me. But the other nurse that came later sat with me and was talking to me about what to do. I felt like I should have delivered at home. I even told my mother to move me [to a different hospital] before the other nurse came in." (IDI participant, 17 years, \#106)

The women hoped for birth attendants to receive them with open arms when they reached the health facility, for birth attendants to be supportive during labour by being helpful, kind and encouraging to women when in labour pains. They hoped for effective communication and some autonomy. Women that experienced such a positive rapport and interaction with health workers expressed happiness with their facility birth experience. Some women even suggested not minding being denied a birth companion or preferred birth position, as long as the birth attendant was supportive through the delivery.

"She [birth attendant] said I should lay down and she sat beside me, later on when the labour pain started again, she came closer to me and asked me to breathe while she was bringing out her hand gloves and all other things she will need for the delivery. After a while, the baby's head came out, and she helped me to bring him out. She was kind to me because when I was crying, she told me not to cry it will soon be over and I will rest." (FGD participant, 29 years, \#102_5)

\section{Failure to meet professional standards of care}

Forty-four percent (95\% CI 24-66) of the women reported experiencing incidences of mistreatment relating to failure to meet professional standards of care. The most commonly reported being a lack of informed consent processes, $25 \%$ of women (95\% CI 11-47). Absence of skilled attendant at the time of delivery, $18 \%$ (95\% CI 6-32), and painful vaginal examination, $18 \%$ (95\% CI $7-$ $41)$, were also commonly reported.

While only $8 \%$ (95\% CI $5-13$ ) of women reported neglect, abandonment or long delays in the exit interviews, in IDIs and FGDs women described profound displeasure at being neglected even though they were in a health facility, being ignored while they needed help, being abandoned to deliver alone while in a health facility and experiencing long delays before receiving attention. Women highlighted experiencing episiotomy without pain relief - even when they expressed pain, or not being asked for consent before procedures. Other important manifestation was the absence of skilled staff, with cleaners and non-clinical staff conducting deliveries. Women freely described their displeasure in relation to this dimension, they did not offer any defence of health worker behaviour or the health system, and did not blame themselves for receiving such mistreatment and saw these as strong reasons for causing reluctance to deliver in a health facility again.

"It had happened to me during my first delivery before the nurse came, the cleaner did everything to me [conducted the delivery]." (FGD participant, 24 years, \#101_8)

"The baby came out with the cord around her neck, so I struggled to remove it off her [on my own]. Before she [health worker] could come to me, I had already removed the cord that was around the baby's neck." (FGD participant, 28 years, \#201_2)

"I had a tear [during delivery], they [health workers] just started the episiotomy without any injection [for pain relief] while they knew that it was a painful procedure, I was not happy at all. They should inform me what they were going to do to have my consent, I think that would have been the right thing to do." (IDI participant, 24 years, \#102)

\section{Physical abuse}

From the exit survey, just 3\% of women (95\% CI 2-4) reported being beaten, pushed, slapped or poked during delivery and only $1 \%(95 \%$ CI $0-3)$ reported experiencing any form of physical restraint (Table 3).

According to women in the IDIs and FGDs, use of force was primarily manifested as women being slapped or hit during labour and delivery, with tying of legs (apart) as the main form of restraint, although respondents were of the view that this rarely occurs in their 
Table 3 Self-reported experience of respectful care during institutional childbirth

\begin{tabular}{|c|c|c|}
\hline Main & Manifestations/indicators & $N=342$ \\
\hline \multicolumn{2}{|l|}{ Dimensions } & $\%(95 \% \mathrm{Cl})$ \\
\hline \multirow[t]{9}{*}{ Health system conditions and constraints } & Poor physical condition of facilities (dirty delivery room) & $27(12-49)$ \\
\hline & Staffing shortages (e.g. not enough staff) during labour and delivery & $24(11-44)$ \\
\hline & Supply constraints (e.g. essential medicines and supply not available) & $13(7-21)$ \\
\hline & Lack of privacy (e.g. feeling of being exposed during delivery) & $15(4-42)$ \\
\hline & Lack of redress & $5(2-11)$ \\
\hline & Bribery and extortion during facility birth & $1(0-3)$ \\
\hline & Feeling of unclear fee structures (e.g. lack of visible price list) & $19(7-44)$ \\
\hline & Feeling of unreasonable requests by health workers & $19(7-44)$ \\
\hline & Experience of any abuse related to health system conditions and constraints & $50(31-70)$ \\
\hline \multirow[t]{12}{*}{ Poor rapport between women and providers } & Poor communication with the BA during labour and delivery & $15(5-37)$ \\
\hline & Dismissal of woman (companion) concerns during labour and delivery & $7(3-14)$ \\
\hline & Had language and interpretation issues during labour and delivery & $3(1-5)$ \\
\hline & Poor staff attitudes during labour and delivery & $9(5-16)$ \\
\hline & Lack of supportive care from health workers & $18(6-43)$ \\
\hline & Denial or lack of birth companions during labour and delivery & $28(14-49)$ \\
\hline & Being treated as passive participants during childbirth & $7(2-27)$ \\
\hline & Denial of food, fluids, or mobility during labour and delivery & $4(1-18)$ \\
\hline & Lack of respect for preferred birth positions & $13(8-22)$ \\
\hline & Denial of safe traditional practices & $5(1-15)$ \\
\hline & Detained in a facility for failure to pay for services & $6(1-21)$ \\
\hline & Experience of any abuse related to poor rapport between women and providers & $46(24-69)$ \\
\hline \multirow[t]{7}{*}{ Failure to meet professional standards of care } & Lack of informed consent process (e.g. examine without permission) & $25(11-47)$ \\
\hline & Breach of confidentiality (women private information shared) & $1(1-2)$ \\
\hline & Painful vaginal exams (refusal to provide pain relief) & $18(7-41)$ \\
\hline & Neglect, abandonment, or long delays (Ignored when help is needed) & $8(5-13)$ \\
\hline & Skilled attendant absent at time of delivery & $18(6-32)$ \\
\hline & Performance of unconsented surgical operations & $2(1-7)$ \\
\hline & Experience of any abuse related to failure to meet professional standards of care & $44(24-66)$ \\
\hline \multirow[t]{3}{*}{ Physical abuse } & Being beaten, pushed, pinched, slapped or poked & $3(2-4)$ \\
\hline & Physically restrained, tied or gagged during labour and delivery & $1(0-3)$ \\
\hline & Experience of any physical abuse & $3(2-5)$ \\
\hline \multirow[t]{3}{*}{ Verbal abuse } & Harsh or rude language, judgmental or accusatory comments & $10(6-18)$ \\
\hline & Threats of withholding treatment or blamed for poor birth outcomes & $6(3-12)$ \\
\hline & Experience of any verbal abuse & $11(6-20)$ \\
\hline \multirow[t]{2}{*}{ Sexual abuse } & Sexual abuse touched inapproachably or raped & 0 \\
\hline & Any sexual abuse & 0 \\
\hline \multirow[t]{2}{*}{ Stigma \& discrimination } & Discriminated against based on ethnicity, religion, income, disease & 0 \\
\hline & Experience of any abuse related to discrimination & 0 \\
\hline Experience of any abuse & & $66(45-82)$ \\
\hline
\end{tabular}

setting. Rather, they felt that physical abuse of this kind was limited to a few specific health workers and done to exert compliance or obedience. Where it had been experienced, women reported dealing with physical abuse in different ways, for example, by mostly ignoring the mistreatment, focusing on their goal to deliver safely and receiving the help that took them to the hospital in the first place. One woman reported fighting back. A 
commonly held view among women in IDIs and FGDs was that the blame lay with the women in labour for instigating the slapping, hitting or tying of legs, rather than with the health workers. Physical abuse did not seem to be a deterrent for choosing to have a subsequent birth at a health facility. Women reported being able to identify an abusive health worker from antenatal care visits and subsequently choosing to go to a different facility to avoid her or him.

"I was not married [young] when I had my first birth, you know there was shyness at that age. I went to deliver with my pants on, the nurse asked me to pull my pants down, but I was reluctant. She [Nurse] insisted resulting with the two of us both pulling at my pant, that was when she slapped me." (IDI participant, 24 years, \#103)

"They usually slap women during delivery because they might ask you to do something if you refused to comply because of the labour pains they will slap you. That is their work, and maybe you didn't behave well." (IDI participant, 20 years, \#202)

"Though I was not happy, I have no option than to come back [to the health facility]. She [a particular health worker] is always the talk of the village, nobody is happy about her, she is not nice, only she behaves that way [shouting or hitting], but the others [health workers] are good." (IDI participant, 25 years, \#108)

\section{Verbal abuse}

In the exit interviews, $11 \%$ (95\% CI 6-20) of women reported experiencing forms of verbal abuse. Use of harsh, rude or judgemental language or comments were experienced by $10 \%$ (95\% CI 6-18) of women, while 6\% (95\% CI 3-12) reported being threatened and or blamed during labour and delivery.

A common manifestation of verbal abuse recounted by women in IDIs and reinforced in FGDs, included health care workers being unfriendly, shouting or scolding women. Forms of threats and blame manifested as being blamed for poor childbirth outcomes, or being rushed, for instance; asked to hurry and deliver, or being left alone with no attention during labour. In the FGDs women expressed frustration at being verbally assaulted in addition to their labour pains. Some tried to justify frequent verbal assaults by health workers during labour or delivery, attributing the verbal abuse to the wailing and screaming of women during delivery. Despite verbal abuse, nearly all the women in IDIs and FGDs described the medication or drugs, injections and assistance from the health workers as sufficient motivation to deliver in a health facility again, with just a few saying it would be better to deliver at home with dignity. Suggested mechanisms to avoid verbal abuse included obeying all orders by health care workers, going to the health facility prepared with all the required birth items, e.g. gloves, pampers or baby napkins, attending antenatal care and being patient with labour pains, i.e. not crying or shouting.

"They have never done it to me, but I once escorted a woman to the home. [After a prolonged labour] she gave birth, but the baby has already died in her stomach [still birth]. You know delivering a live baby and the baby that is lifeless is different because a live baby helps you in the process of coming out, unlike the one that is lifeless...they kept telling her...that she was the one that killed her baby...that she is used to doing that every time, that her babies don't come out alive. Honestly, I was angry with them." (IDI participant, 32 years, \#201)

\section{Sexual abuse}

Questions around experience of sexual abuse were adapted for the Gombe context to include touching the sexual organs of a woman in labour with sexual intent, gestures suggestive of sexual interest, selective attention suggestive of sexual interest, or rape. No women reported experiencing sexual abuse.

Similarly, none of the respondents from the FGDs or IDIs could describe a sexual abuse incident, either based on their own or another's experience. An FGD participant described her discomfort at being attended by a male birth attendant, which she found unsettling, she described not being able to go back to the same facility for a long time. An opinion shared by many in the group but not all. In general, women were uncomfortable talking about the subject of sexual abuse.

\footnotetext{
"You know women don't want a male health care worker to conduct their delivery. One will prefer a female to do that. If a male health worker is the one that conducted your delivery, you would not feel comfortable anytime you see him. This can make one to either deliver at home or move to another facility... since my delivery, anytime I go to the health facility and see him [the male health worker] I feel uncomfortable." (FGD participant, 37 years, \#201_4)
}

\section{Stigma and discrimination}

Only one woman among the exit interviewees reported experiencing an act, a gesture or being treated negatively because of her tribe, religion, socioeconomic status, disease condition, or age (0.3\%). 
Differing opinions were expressed during qualitative interviews (IDIs and FGDs), again with the majority of women talking about stigma and discrimination they had witnessed, rather than what they had experienced themselves. Manifestations highlighted included women from the city being given preferential treatment over women from the village, those considered rich treated better than those considered poor, and people from the same religion or tribe as the health care worker being treated preferentially. Women also described being treated negatively when they went to health care facilities outside their community, catchment areas or LGA.

"Yes, they discriminate, especially to a village person. I swear, they show discrimination. You cannot say you are from the village without them [health workers] giving you a nasty look, dust and scorn." (IDI participant, 20 years, \#206)

"...it was due to the lack of medical attention here in the health facility serving our community that made her go to Bula hospital [health facility serving a different community]. The health workers there did not receive us well, and they said why don't we go to the facility in our community for treatment, why disturb them here?" (FGD participant, 28 years, \#201_8)

However, some participants insisted that such practices do not occur in their facilities.

"The hospital where I went there was no discrimination. Even though our tribe and religion were not the same [as the health workers], but honestly, ...they even treat us better than the ones [health workers] who are of the same tribe and religion as us. We enjoyed going there, there was no argument." (IDI participant, 32 years, \#207)

\section{Discussion}

Mistreatment was reported in $66 \%$ of all institutional births, with reported prevalence varying across the dimensions of care. Women's reported experience of mistreatment predominantly arose because of health system conditions and constraints (50\% of all women) and instances of mistreatment related to a poor rapport between women and providers ( $46 \%$ of all women). Mistreatment related to sexual abuse, stigma and discrimination were reported the least. Qualitative findings highlighted different forms of mistreatment that might take place during institutional births and that mistreatment could affect subsequent decisions about where to deliver.
Our findings of frequent mistreatment during institutional delivery in northeast Nigeria are consistent with findings both from other low and middle- income settings $[2,16-18,20,21,23,38-46]$ and from other regions in Nigeria [47-51], underscoring the need for country and global advocacy to address women's experiences of care during institutional delivery [12, 52]. However, the different dimensions of abuse were not consistently reported between settings. In different settings in Nigeria for example, reported prevalence of physical abuse ranged from 2 and 36\% (3\% in this study), discrimination from 0 and $20 \%$ (0\% in this study) and neglect and abandonment ranged from 8 and 24\% (8\% in this study) [24]. This emerging pattern of high frequency of negative experience but heterogeneity in the dimensions, suggests that strategies for improvement need to take account of contextual differences [2]. The qualitative data further emphasised some of these nuances, revealing women value being received with open arms when they first arrive at a health facility and being supported, treated kindly and encouraged through the birthing process. They appreciate when their choices and concerns are considered, and when a birth attendant communicates with them effectively. Moreover, a unique manifestation of mistreatment from the qualitative findings concerned women being discriminated against when they deliver in health facilities outside their catchment area or communities, underlining what matters and what works may differ from one setting to another.

Participants in the qualitative interviews were likely to have attended any of the ten primary health care facilities. They were selected to describe how mistreatment occurs in Gombe State. Although the exit interviewees were more likely to be multigravida, married, Muslims and Fulani's than the qualitative interviewees, we do not expect this to have changed the conclusions arising from this study, as the results are supposed to be complimentary, not to converge to provide the same conclusions [53]. This study provided complimentary results relating to two different aspects of mistreatment: (1) the frequency with which mistreatment occurs in Gombe state, and (2) the presentation of mistreatment when it occurs [53].

\section{Implications for quality of care}

This study presents the first evidence of mistreatment during institutional delivery in Gombe State. Mistreatment appears to be a deterrent to utilisation of $\mathrm{MNH}$ services in Gombe. These findings taken together with findings from other settings in Nigeria may be an indication of why delivery at home continues to be a more attractive option for women in Nigeria. Women are aware of the possibility of going to the facility and not meeting a health worker, and that even if they do, the health 
worker may not be skilled. Women anticipate that the labour and delivery environment may not be ideal (e.g. no water, not clean, disturbed by mosquitos, no screen to provide privacy). They are aware that in addition to surviving the poor state of the health facilities, they may have to cope with one or more overworked and less motivated health workers with a poor attitude.

To improve the birth environment in health facilities in the country, Nigeria is promoting a task-shifting and sharing policy [54]. The task-shifting policy aims to improve access to skilled birth attendants and to address the health worker shortages especially at PHCs where about $90 \%$ of deliveries are conducted by lower cadre health workers (i.e. CHEW, JCHEWS). One specific objective of the task-shifting policy is to train the CHEWs to a level that they can provide routine maternal and newborn care, basic emergency obstetrics and newborn care, and referral for comprehensive emergency obstetric and newborn care when needed [54]. Studies on the experience of care in Nigeria, including findings from this study, suggest the need to emphasise respectful maternity care in the task-shifting policy recommendations and curriculum for frontline health care workers in Gombe State and Nigeria as a whole. So that when CHEWS are the only birth attendant available in a health facility, as was the case in our study sites, they can provide quality care both in terms of content and experience of care. The Community Health Influencers, Promoters, and Services programme (CHIPS), is another initiative of the federal government of Nigeria, designed to link communities with the health system through community outreach [55]. The CHIPS program could be utilised in Gombe and in Nigeria to also educate communities about women's rights to respectful maternity care.

We found that the incidence of mistreatment due to health system conditions and constraints appeared to be a strong deterrent to the subsequent use of health facilities for delivery. Under-resourced and strained health systems have been associated with increased incidence of disrespect and abuse in other settings $[48,49,56]$ and consequently the delayed utilization or non-utilization of institutional delivery services [5, 51, 61, 58]. Accordingly, interventions that seek to address mistreatment in the study setting and other similar settings, should emphasize addressing system-wide constraints [20, 59-61]. For example, when two or three women seek delivery care simultaneously, at a health centre with only two rooms for inpatient and outpatient services and only two health staff on duty, those women are likely to experience forms of mistreatment aligned with health system constraints. In this scenario, women may experience a lack of privacy in the delivery room, or a lack of prompt attention due to shortages of health care workers.
Addressing system-wide constraints is challenging in resource-limited settings such as Gombe, but possible. For example, stakeholders in Gombe including policymakers, health care providers, women and communities, could come together to review these findings, negotiate standards of care for labour and childbirth [62] and agree on contextually appropriate ways to institutionalise the agreed standards in health facilities to improve women's experience of care. Such an approach has already been successfully tried in two settings of Nigeria [62] and is worth considering in Gombe and other similar settings.

\section{Strengths and limitations}

This study provides a rich description of the frequency of indicators of mistreatment during institutional delivery, and women's own views about the experience of care. Nonetheless it has limitations. The exit interviews were conducted within health facilities, a possible source of courtesy bias [19]. To minimise this, respondents were interviewed away from the facility staff and assured anonymity and confidentiality [63]. Additionally, we excluded women discharged without a live baby, which had the potential to affect our estimates due to differential risks for reporting mistreatment [19]. The health facilities were not selected to represent the state, limiting generalisability. Our study tool was based on women's self-report of perceived mistreatment, which may not be an accurate reflection of all mistreatment, and sample size restrictions limited any tests for association. Nonetheless, the study provided evidence of prevalence of mistreatment during institutional delivery in Gombe State that was previously lacking. The exit interviews were conducted within $24 \mathrm{~h}$ post-partum and women's reflections on the birthing experience may be different to women interviewed later after birth $[64,65]$. In some studies, exit interviews have been complimented with community interviews with women 4-10 weeks post-delivery to compare what women reported at exit [64, 66]. Our qualitative sample comprised of women whose infants were about 6-months old, meaning that they had more time to reflect on their facility birth experience. However, the two data sources were designed to be complementary, with the qualitative data further elaborating and illustrating the manifestations of mistreatment.

\section{Conclusions}

Our study showed that mistreatment during institutional delivery is frequent in northeast Nigeria and risks jeopardising efforts to increase the coverage of institutional deliveries. To address this problem, immediate and sustained attention to the quality of care as it pertains to the experience of care users is needed. 


\section{Supplementary information}

Supplementary information accompanies this paper at https://doi.org/10. 1186/s12978-019-0837-z.

Additional file 1: Table S1. Mistreatment questions.

\section{Abbreviations}

Cl: Confidence Interval; COREQ: Consolidated Criteria for Reporting Qualitative Research; CSPro: Census and Survey Processing System; FGDs: Focus Group Discussions; IDIs: In-depth interviews

\section{Acknowledgements}

The authors would like to thank Data Research and Mapping Consult for Coordinating the data collection, the Gombe State Primary Health Care Development Agency, Gombe State Ministry of Health, our partners Society for Family Health and Pact Nigeria, and study participants for their cooperation and participation in the study.

\section{Authors' contributions}

$\mathrm{NU}, \mathrm{TM}$, conceptualized and designed the study; NU, conducted the analysis and drafted the manuscript; NU, DW, ZH, UA and TM revised the manuscript and provided critically important intellectual content; all authors read and approved the final manuscript.

\section{Funding}

This work was supported by IDEAS - Informed Decisions for Actions to improve maternal and newborn health (http://ideas.Ishtm.ac.uk), which is funded through a grant from the Bill \& Melinda Gates Foundation to the London School of Hygiene \& Tropical Medicine. (Gates Global Health Grant Number: OPP1149259).

\section{Availability of data and materials}

The datasets used and/or analysed during the current study are available from the corresponding author on reasonable request.

\section{Ethics approval and consent to participate}

This research was conducted with approval from the Federal Ministry of Health Abuja, Nigeria, the State Ministry of Health Gombe State, Nigeria and the London School of Hygiene \& Tropical Medicine (reference 12181). The free and signed informed consent of all interviewees was obtained.

\section{Consent for publication}

Not applicable.

\section{Competing interests}

The authors declare that they have no competing interests.

\section{Author details}

'Department of Disease Control, London School of Hygiene \& Tropical Medicine, London WC1E 7HT, UK. IInstitute for Global Health, University College London, London, UK. ${ }^{3}$ Data Research \& Mapping Consult, Abuja, Nigeria.

Received: 22 January 2019 Accepted: 15 November 2019

Published online: 02 December 2019

\section{References}

1. Tunçalp Ö, Were W, MacLennan C, Oladapo O, Gülmezoglu A, Bahl R, et al. Quality of care for pregnant women and newborns-the WHO vision. BJOG An Int J Obstet Gynaecol. 2015;122:1045-9. https://doi.org/10.1111/14710528.13451

2. Banks KP, Karim AM, Ratcliffe $H L$, Betemariam W, Langer A. Jeopardizing quality at the frontline of healthcare: prevalence and risk factors for disrespect and abuse during facility-based childbirth in Ethiopia. Health Policy Plan. 2018;33:317-27. https://doi.org/10.1093/heapol/czX180.

3. Montagu D, Sudhinaraset M, Diamond-Smith N, Campbell O, Gabrysch S, Freedman L, et al. Where women go to deliver: understanding the changing landscape of childbirth in Africa and Asia. Health Policy Plan. 2017;32:1146-52. https://doi.org/10.1093/heapol/czx060.
4. National Population Commission (NPC) [Nigeria] and ICF. Nigeria Demographic and Health Survey 2018 Key Indicators Report. Abuja, Nigeria, and Rockville, Maryland, USA: NPC and ICF; 2019.

5. Ashimi AO, Amole TG. Prevalence, reasons and predictors for home births among pregnant women attending antenatal care in Birnin kudu, Northwest Nigeria. Sex Reprod Healthc. 2015;6:119-25. https://doi.org/10.1016/j. srhc.2015.01.004.

6. Okonofua F, Ntoimo L, Ogungbangbe J, Anjorin S, Imongan W, Yaya S. Predictors of women's utilization of primary health care for skilled pregnancy care in rural Nigeria. BMC pregnancy childbirth. BMC Pregnancy and Childbirth. 2018;18:1-15. https://doi.org/10.1186/s12884-018-1730-4.

7. Bohren MA, Hunter EC, Munthe-Kaas HM, Souza JP, Vogel JP, Gülmezoglu AM. Facilitators and barriers to facility-based delivery in low- and middleincome countries: a qualitative evidence synthesis. Reprod Health. 2014. https://doi.org/10.1186/1742-4755-11-71.

8. Kassebaum NJ, Bertozzi-Villa A, Coggeshall MS, Shackelford KA, Steiner C, Heuton KR, et al. Global, regional, and national levels and causes of maternal mortality during 1990-2013: a systematic analysis for the global burden of disease study 2013. Lancet. 2014. https://doi.org/10.1016/S01406736(14)60696-6.

9. Say L, Chou D, Gemmill A, Tunçalp Ö, Moller AB, Daniels J, et al. Global causes of maternal death: a WHO systematic analysis. Lancet Glob Heal. 2014. https://doi.org/10.1016/S2214-109X(14)70227-X

10. Campbell OMR, Calvert C, Testa A, Strehlow M, Benova L, Keyes E, et al. The scale, scope, coverage, and capability of childbirth care. Lancet. 2016. https://doi.org/10.1016/S0140-6736(16)31528-8.

11. Souza JP, Gülmezoglu AM, Vogel J, Carroli G, Lumbiganon P, Qureshi Z, et al. Moving beyond essential interventions for reduction of maternal mortality (the WHO multicountry survey on maternal and newborn health): a cross-sectional study. Lancet. 2013. https://doi.org/10.1016/S01406736(13)60686-8.

12. Kruk ME, Gage AD, Arsenault C, Jordan K, Leslie HH, Roder-DeWan S, et al. The lancet Global Health Commission on high-quality health systems in the SDG era: time for revoluttion. Lancet Glob Health. 2017. https://doi.org/10. 1016/S2214-109X(17)30101-8.

13. Kruk ME, Gage AD, Joseph NT, Danaei G, García-Saisó S, Salomon JA. Mortality due to low-quality health systems in the universal health coverage era: a systematic analysis of amenable deaths in 137 countries. Lancet. 2018; 6736. https://doi.org/10.1016/S0140-6736(18)31668-4.

14. Shakibazadeh E, Namadian M, Bohren MA, Vogel JP, Rashidian A, Nogueira Pileggi $V$, et al. Respectful care during childbirth in health facilities globally: a qualitative evidence synthesis. BJOG. 2018:932-42. https://doi.org/10.1111/ 1471-0528.15015.

15. Jewkes R, Penn-Kekana L. Mistreatment of women in childbirth: time for action on this important dimension of violence against women. PLoS Med. 2015. https://doi.org/10.1371/journal.pmed.1001849.

16. Savage $V$, Castro A. Measuring mistreatment of women during childbirth: a review of terminology and methodological approaches prof. Suellen Miller. Reprod Health. 2017. https://doi.org/10.1186/s12978-017-0403-5.

17. Bowser D, Hill K. Exploring evidence for disrespect and childbirth, in facilitybased analysis, report of a landscape [Internet]: USAID Traction Project; 2010. Available: https://www.ghdonline.org/uploads/Respectful_Care_at_ Birth 9-20-101_Final1.pdf. Accessed 20 Jan 2019

18. Bohren MA, Vogel JP, Hunter EC, Lutsiv O, Makh SK, Souza JP, et al. The mistreatment of women during childbirth in health facilities globally: a mixed-methods systematic review. PLoS Med. 2015;12. https://doi.org/10. 1371/journal.pmed.1001847.

19. Sando D, Abuya T, Asefa A, Banks KP, Freedman LP, Kujawski S, et al. Methods used in prevalence studies of disrespect and abuse during facility based childbirth: lessons learned prof. Suellen Miller. Reprod Health. 2017; 14:1-18. https://doi.org/10.1186/s12978-017-0389-z.

20. Ratcliffe HL, Sando D, Lyatuu GW, Emil F, Mwanyika-Sando M, Chalamilla G, et al. Mitigating disrespect and abuse during childbirth in Tanzania: an exploratory study of the effects of two facility-based interventions in a large public hospital. Reprod Health. 2016;13. https://doi.org/10.1186/s12978-016-0187-z.

21. Rosen HE, Lynam PF, Carr C, Reis V, Ricca J, Bazant ES, et al. Direct observation of respectful maternity care in five countries: a cross-sectional study of health facilities in east and southern Africa. BMC Pregnancy Childbirth. 2015;15. https://doi.org/10.1186/s12884-015-0728-4.

22. Warren C, Njuki R, Abuya T, Ndwiga C, Maingi G, Serwanga J, et al. Study protocol for promoting respectful maternity care initiative to assess, 
measure and design interventions to reduce disrespect and abuse during childbirth in Kenya. BMC Pregnancy Childbirth. 2013;13:1-9. https://doi.org/ 10.1186/1471-2393-13-21.

23. Abuya T, Ndwiga C, Ritter J, Kanya L, Bellows B, Binkin N, et al. The effect of a multi-component intervention on disrespect and abuse during childbirth in Kenya. BMC Pregnancy Childbirth. 2015. https://doi.org/10.1186/s12884015-0645-6

24. Ishola F, Owolabi O, Filippi V. Disrespect and abuse of women during childbirth in Nigeria: a systematic review. PLoS One. 2017;12:1-17. https:// doi.org/10.1371/journal.pone.0174084.

25. Federal Ministry of Health (FMoH). National Healtth Facility Survey [Internet] 2017. Available: http://somlpforr.org.ng/wp-content/uploads/2017/05/NHFSFinal-Report-for-Printing_VI.pdf Accessed 10 Oct 2019.

26. National Bureau of Statistics (NBS) and United Nations Children's Fund (UNICEF). Multiple Indicator Cluster Survey 2016-17, Survey Findings Report. Abuja: National Bureau of Statistics and United Nations Children's Fund; 2018. p. 1-12. Available: https://www.unicef.org/nigeria/sites/unicef.org. nigeria/files/2018-09/Nigeria-MICS-2016-17.pdf

27. National Population Commission (NPC) [Nigeria] and ICF International. Nigeria Demographic and Health Survey 2013. Abuja and Rockville: NPC and ICF International; 2014

28. Alkali Y, Jalo I, El-Nafaty A, Bode-Thomas F. Causes of stillbirth in a community survey in Gombe State. Niger J Paediatr. 2014;41:125. https:// doi.org/10.4314/njp.v41i2.9

29. Basheer Yahya M, Pumpaibool T. Factors affecting women-willingness to pay for maternal, neonatal andChild health services (MNCH) in Gombe state, Nigeria. J Womens Heal Care. 2017;06. https://doi.org/10.4172/2167-0420. 1000404.

30. Yahya MB, Pumpaibool T. Factors influencing the decision to choose a birth center by pregnant women in Gombe state Nigeria: baseline survey. J Heal Res. 2019:33:228-37. https://doi.org/10.1108/JHR-10-2018-0129.

31. National Population Commission of Nigeria. Nigeria Demographic and Health Survey 2013. National Population Commission. 2014. https://doi.org/ 10.1111/j.1728-4465.2008.00154.x

32. Gombe State Government. History of Gombe State, Nigeria 2018 [Internet] 2018. Available: http://gombestate.gov.ng/history-2. Accessed 20 Jan 2019.

33. Oruonye ED, Abubakar H, Ahmed MY, Dan Y. HIV/AIDS Interventions in Gombe State Nigeria; Challenges of Sustaining the Gains. Int J Asian Soc Sci. 2017;7:448-57. https://doi.org/10.18488/journal.1.2017.76.448.457.

34. National Population Commission (NPC) [Nigeria] and ICF. Nigeria Demographic and Health Survey Key Indicators Report. Abuja and Rockville: National Population Commission (NPC) [Nigeria] and ICF; 2019.

35. Bhattacharya AA, Umar N, Audu A, Allen E, Schellenberg JRM, Marchant T. Quality of routine facility data for monitoring priority maternal and newborn indicators in DHIS2: a case study from Gombe state, Nigeria. PLoS One. 2019;14:1-21. https://doi.org/10.1371/journal.pone.0211265.

36. Gombe State Ministry of Health $(\mathrm{SMoH})$. Gombe state framework for the implimentation of expanded access to family planning services [Internet]. Gombe (Nigeria); 2012. Available: https://www.fhi360.org/sites/default/files/ media/documents/nigeria-gombe-state-framework.pdf.

37. Tong A, Sainsbury P, Craig J. Consolidated criteria for reporting qualitative research (COREQ): a 32-item checklist for interviews and focus groups. Int J Qual Heal Care. 2007;19:349-57. https://doi.org/10.1093/intqhc/mzm042.

38. Boynton P, Greenhalgh T. Selecting, designing, and developing your questionnaire. Bmj. 2004;328:1312-5. https://doi.org/10.1136/bmj.328.7451.1312.

39. Dworkin SL. Sample size policy for qualitative studies using in-depth interviews. Arch Sex Behav. 2012;41:1319-20. https:/doi.org/10.1007/s10508-012-0016-6.

40. Bengtsson M. How to plan and perform a qualitative study using content analysis. NursingPlus Open Elsevier. 2016;2:8-14. https://doi.org/10.1016/j. npls.2016.01.001

41. Guest G, Namey E, McKenna K. How many focus groups are enough? Building an evidence base for nonprobability sample sizes. Field methods. 2017;29:3-22. https://doi.org/10.1177/1525822X16639015

42. Tynan AC, Drayton JL. Conducting focus groups - a guide for first-time users. Mark Intell Plan. 1988;6:5-9. https://doi.org/10.1108/eb045757.

43. Ouédraogo A, Kiemtoré S, Zamané $H$, Bonané BT, Akotionga M, Lankoande J. Respectful maternity care in three health facilities in Burkina Faso: the experience of the Society of Gynaecologists and Obstetricians of Burkina Faso. Int J Gynecol Obstet. 2014;127:S40-2.

44. Bradley S, McCourt C, Rayment J, Parmar D. Disrespectful intrapartum care during facility-based delivery in sub-Saharan Africa: a qualitative systematic review and thematic synthesis of women's perceptions and experiences. Soc Sci Med. 2016;169:157-70.

45. Burrowes S, Holcombe SJ, Jara D, Carter D, Smith K. Midwives' and patients' perspectives on disrespect and abuse during labor and delivery care in Ethiopia: a qualitative study. BMC Pregnancy Childbirth. 2017:17:1-14.

46. Downe S, Lawrie TA, Finlayson K, Oladapo OT. Effectiveness of respectful care policies for women using routine intrapartum services: a systematic review. Reprod Health. 2018;15:1-13.

47. Okafor II, Ugwu EO, Obi SN. Disrespect and abuse during facility-based childbirth in a low-income country. Int J Gynecol Obstet. 2014:110-3. https://doi.org/10.1016/j.ijgo.2014.08.015.

48. Igboanugo GM, Martin $\mathrm{CH}$. What are pregnant women in a rural Niger Delta community's perceptions of conventional maternity service provision? An exploratory qualitative study. [Internet]. African journal of reproductive health. Women's Health and Action Research Centre; 2011. doi:https://doi. org/10.2307/41762346

49. Uzochukwu BSC, Onwujekwe OE, Akpala CO. Community satisfaction with the quality of maternal and child health services in Southeast Nigeria [Internet]. East Afr Med J. 2004. https://doi.org/10.4314/eamj.v81i6.9178.

50. Udoma EJ, Ekanem AD, Abasiattai AM, Bassey EA. Reasons for preference of delivery in spiritual church-based clinics by women of south-South Nigeria. Niger J Clin Pract. 2008;11:100-3.

51. Iyaniwura C, Yussuf Q. Utilization of antenatal care and delivery services in Sagamu, south western Nigeria. Afr J Reprod Health. 2009;13:111-22 Available: http://ovidsp.ovid.com/ovidweb.cgi?T=JS\&PAGE=reference\&D= emed9\&NEWS $=\mathrm{N} \& A N=20690266$.

52. Al-Janabi A, Al-Wahdani B, Ammar W, Arsenault C, Asiedu EK, Etiebet $M-A$, et al. Bellagio declaration on high-quality health systems: from a quality moment to a quality movement. Lancet Glob Heal. 2018:3-4. https://doi.org/10.1016/S2214-109X(18)30372-3.

53. Heale R, Forbes D. Understanding triangulation in research. Evid Based Nurs. 2013;16:98. https://doi.org/10.1136/eb-2013-101494.

54. Federal Ministry of Health. Task Shifting and Task Sharing Policy for Maternal and Newborn Health. 2013

55. National Primary Health Care Development Agency. Community health influencers, promoters, and services Programme (CHIPS). Abuja; 2018. Available at https://nphcda.gov.ng/special-programmes/chips/. Accessed 10 Oct 2019

56. Onah HE, Ikeako LC, lloabachie GC. Factors associated with the use of maternity services in Enugu, southeastern Nigeria. Soc Sci Med Pergamon. 2006;63:1870-8. https://doi.org/10.1016/j.socscimed.2006.04.019.

57. Moronkola OA, Omonu JB, lyayi DA, Tiamiyu MA. Perceived determinants of the utilization of maternal health-care services by rural women in Kogi state, Nigeria. Trop Doct. 2007. https://doi.org/ 10.1258/004947507780609365.

58. Moore BM, Alex-Hart BA, George IO. Utilization of health care services by pregnant mothers during delivery: a community based study in Nigeria. East Afr J Public Health. 2011. https://doi.org/10.11694/pamj.supp.2014.17.1. 3596

59. Ratcliffe HL, Sando D, Mwanyika-Sando M, Chalamilla G, Langer A, McDonald KP. Applying a participatory approach to the promotion of a culture of respect during childbirth. Reprod Health. 2016. https://doi.org/10. 1186/s12978-016-0186-0.

60. Freedman LP, Kruk ME. Disrespect and abuse of women in childbirth: Challenging the global quality and accountability agendas. Lancet. 2014 e42-4. https://doi.org/10.1016/S0140-6736(14)60859-X.

61. McMahon SA, Mnzava RJ, Tibaijuka G, Currie S. The "hot potato" topic: challenges and facilitators to promoting respectful maternal care within a broader health intervention in Tanzania prof. Suellen Miller. Reprod Health. 2018;15:1-6. https://doi.org/10.1186/s12978-018-0589-1.

62. Oladapo OT, Bohren MA, Fawole B, Mugerwa K, Ojelade OA, Titiloye MA et al. Negotiating quality standards for effective delivery of labor and childbirth care in Nigeria and Uganda. Int J Gynecol Obstet. 2017;139:47-55. https://doi.org/10.1002/ijgo.12398.

63. Tourangeau R, Yan T. Sensitive questions in surveys. Psychol Bull. 2007;133: 859-83. https://doi.org/10.1037/0033-2909.133.5.859.

64. Kruk ME, Kujawski S, Mbaruku G, Ramsey K, Moyo W, Freedman LP. Disrespectful and abusive treatment during facility delivery in Tanzania: a facility and community survey. Health Policy Plan. 2018:33:e26-33. https:// doi.org/10.1093/heapol/czu079. 
65. Glick P. How reliable are surveys of client satisfaction with healthcare services? Evidence from matched facility and household data in Madagascar. Soc Sc Med. 2009. https://doi.org/10.1016/j.socscimed.2008.09.053.

66. Sando D, Kendall T, Lyatuu G, Ratcliffe H, McDonald K, Mwanyika-Sando M, et al. Disrespect and abuse during childbirth in Tanzania: are women living with HIV more vulnerable? J Acquir Immune Defic Syndr. 2014;67:S228-34.

\section{Publisher's Note}

Springer Nature remains neutral with regard to jurisdictional claims in published maps and institutional affiliations.

Ready to submit your research? Choose BMC and benefit from:

- fast, convenient online submission

- thorough peer review by experienced researchers in your field

- rapid publication on acceptance

- support for research data, including large and complex data types

- gold Open Access which fosters wider collaboration and increased citations

- maximum visibility for your research: over $100 \mathrm{M}$ website views per year

At BMC, research is always in progress.

Learn more biomedcentral.com/submissions 